\title{
WHAT IF WE UNDERSTOOD THE ROLE UNDERWATER PLANTS PLAY IN THE FLOW OF WATER?
}

DR XIAO YU, BASED AT THE UNIVERSITY OF FLORIDA IN THE US, IS THE PRINCIPAL INVESTIGATOR OF A PROJECT THAT SEEKS TO MODEL THE FLOW OF WATER OVER SUBMERGED AQUATIC VEGETATION. THE FINDINGS WILL HELP SCIENTISTS STUDY A VARIETY OF KEY ECOSYSTEM PROCESSES IN RIVERS AND ESTUARIES

\section{TALK LIKE A COASTAL AND OGFANOGRAPHIC ENGINEFR}

\section{SUBMERGED AQUATIC VEGETATION a rooted aquatic plant that grows completely under water}

VEGETATION BLADE - the expanded part of a leaf or petal

BLADE-TO-BLADE INTERACTIONS - when multiple vegetation blades come into contact and interact with each other

DEFLECTED HEIGHT - the height of the vegetation blade when submerged under water. The deflected height is different from the length of the vegetation blade because the vegetation blade bends under the flow of water

HYDRODYNAMICS - a branch of physics that deals with the motion of fluids and the forces acting on solid bodies immersed in fluids (and hence the resistance forces acting on the fluid by solid bodies)

FLOW ATTENUATION - the action of slowing down the flow of water

TURBULENCE - fluid motion characterised by chaotic changes in pressure and flow velocity. Turbulence can be seen in everyday phenomena such as surf and fast flowing rivers

FLOW VELOCITY - the distance travelled by a fluid per time i.e., metre/second or feet/minute

MODELLING - the generation of a physical, conceptual or mathematical representation of a real phenomenon that is difficult to observe directly
NATURAL RESOURCES MANAGEMENT using natural resources (land, water, soil, etc.) in a way and at a rate that maintains and enhances the resilience of ecosystems and the benefits they provide

TRANSPORT - a term used to describe the way in which rivers pick up and carry materials as they flow downstream

MONAMI - a coherent waving motion in flexible blades

\section{CAUCHY NUMBER - the ratio of}

hydrodynamic drag force to the elastic restoration force. Visit this website for a revision of forces and elasticity: www.bbc.co.uk/bitesize/guides/ zt9smsg/revision/2
Submerged aquatic vegetation (SAV) is a term that refers to aquatic plants that grow completely under water. These plants reside in both freshwater and saltwater, but in estuaries - where both fresh and saltwater are often mixed together - they can be particularly important for aquatic organisms, which rely on SAV for food and shelter.

Indeed, SAV is a critical part of the ecosystems that exist in bodies of water and plays an important role in rivers and estuaries. If we picture the gentle movement of blades of grass and other vegetation below the surface of rivers and estuaries, we can see that the flow of water runs over and through this vegetation, which affects the flow.

Most of us would take this for granted and think no more of it - but for Dr Xiao Yu, who is a coastal and oceanographic engineer based within the Department of Civil and Coastal Engineering at the University of Florida, the flow of water that runs over and through submerged aquatic vegetation forms the basis of his latest project. His study aims to develop a framework for modelling flow over flexible SAV and quantify the influence of vegetation structural properties and bladeto-blade interactions on hydrodynamics, in particular flow attenuation and turbulent mixing processes.

By understanding the physical-biologicalecological links between the structure of SAV and the ways in which water flows in relation to it, Xiao hopes to uncover findings that will be of critical importance to natural resources management. 



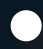 ABOUT COASTAL AND OCEANOGRAPHIC ENGINEERING}

Given the current and future impacts of climate change, now is arguably the most important time for coastal and oceanographic engineering. As the polar icecaps melt, water levels will rise around the world and this will have significant impacts on coastal communities and areas.

Coastal and oceanographic engineering is one notable field that will help to drive research and innovation in areas that will help humanity overcome some of the challenges associated with climate change - not just for human populations, but for the animals and other organisms that rely on ecosystems in and around bodies of water. As Xiao's research shows, it is possible to combine several seemingly independent research interests in order to solve various challenges.

WOULD XIAO RECOMMEND

A CAREER IN COASTAL AND

OCEANOGRAPHIC ENGINEERING?

In a word, yes. Xiao is unequivocal in his passion for the field. "I would definitely recommend a career in the field," explains Xiao. "There are a lot of exciting opportunities in coastal and oceanographic engineering for next-generation scientists and engineers: the sustainable delivery of economic, social and environmental benefits associated with coastal infrastructure; underwater exploration using remotely operated underwater vehicles (ROVs); the floating city by Oceanix that can withstand a Category 5 hurricane."

\section{EXPLORE A CARER IN OGEANOGRAPHIC ENGINEERING}

- Marine Careers is an essential resource for those looking to develop a career in ocean engineering and related fields. This site really should be able to answer any questions you might have: www.marinecareers.net/ocean-engineering

- The University of Florida's College of Engineering provides a wealth of information relating to coastal and oceanographic engineering, including some of the exciting research that is taking place and useful resources: www.eng.ufl.edu

- "We also offer scholarships to high school students and teachers who want to work with our faculty, and graduate students and undergraduate students who want to explore university-level

research," explains Xiao. "The students are given opportunities to present their research at STEM research competitions or during noncompetitive poster sessions."

- In the US, ocean engineers make an average of $\$ 73,000$ per annum, but this is largely dependent on the particular job role being performed. You could be a marine biologist, marine engineer or coasta engineer, to name a few, and all have different average salaries.

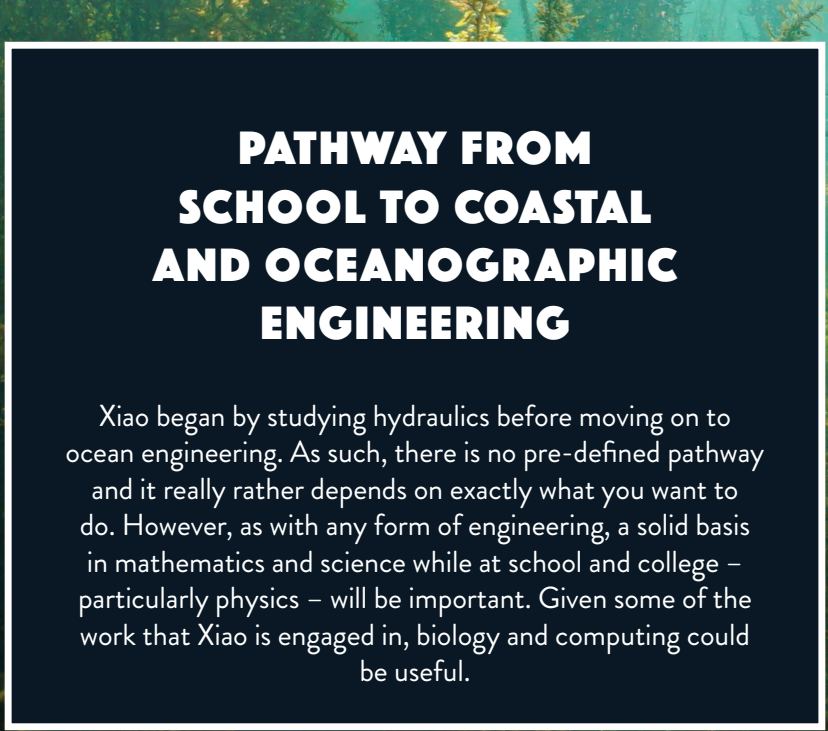

\section{XIAO'S TOP TIPS}

01 Be an active learner. Curiosity has always been the driving force behind research; asking 'why?' and 'how?' will keep science moving forward.

02 Actively seek out research opportunities from an early stage. It will stand you in good stead and give you an idea of what to expect if you pursue a career in academia.

03 Staying motivated is so important for a successful career - if you can find a research topic you are passionate about, half the battle is already won. 


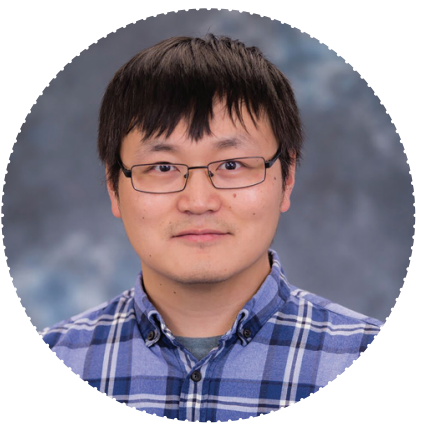

I always wanted to be a scientist when I was younger. My mother was a middle school chemistry teacher and she inspired me to pursue a STEM career.

We constantly face challenging research problems and by working with researchers from other disciplines, I am exposed to new ideas and perspectives, which enables me to see things from different angles. I also enjoy learning about new technologies (such as machine learning) and applying them in my own research.

My long-term goal as an educator is to engage students in interdisciplinary STEM careers and prepare them by imbuing them with the skills they need to solve challenging, practical engineering problems. One of the greatest challenges the US is facing now in graduate-level engineering programmes is the decreasing number of undergraduate students who pursue their studies for career development in the highly challenging technology area - particularly underrepresented and women students. It is, therefore, very important to develop effective ways to engage students to pursue STEM careers by offering them first-hand research experience opportunities so they can realise the benefits.

\section{$\bullet$ MEET ROB}

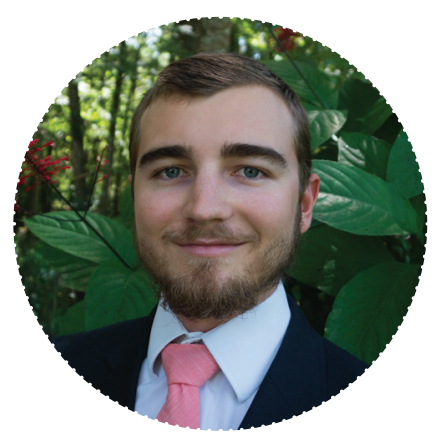

Rob Taylor is an undergraduate student in environmental engineering at the University of Florida, working with Xiao on the NSF-funded project: A framework for modelling flow over flexible submerged aquatic vegetation.

My role in the project is primarily validating model results with field observations. The work is varied, ranging from building mounts for the cameras and velocity instruments, to scuba diving and running the experiment in the field, and analysing the images to extract the data we are looking for.

I was never the child who knew exactly what I wanted to do with my life. In fact, I didn't even want to attend college after high school. The pragmatic and hardworking side of me thought I would be a charter fisherman, and the creative in me wanted to pursue music or filmmaking. However, after encouragement from many family members and friends, and without feeling forced into it, I decided to attend community college. I eventually landed on environmental engineering for my bachelor's degree because of my long history with Florida's ecosystems.

Solving math and physics problems really stimulates my mind in a unique and pleasurable way. As I have moved along in my studies, and systems have gotten more complex, I've started to realise that so many of the engineering problems that we solve just boil down to a collection of physics problems like those learned in the early years of my studies. I also love how so many of the topics we study can be directly applied in industry and help the environment.

\section{Immediately after graduation, I plan on working} in environmental consulting for some time. The position I'm in now keeps me in the field for 20-25 hours a month doing mostly flow monitoring on Florida rivers for public projects. I will likely stay with the company after graduation and fill the rest of my hours with engineering work such as hydrologic modelling, coastal design, geographic information systems (GIS) work and data analysis.

In the end, I want to be able to make a direct impact in areas like environmental protection and ecological restoration, educate the public about climate systems and how humans impact them, and help solve the technical, social, economic and political issues that will undoubtedly come along with climate change. 